\title{
Reducing slab track vibration into bridge using elastic materials in high speed railway
}

\author{
T. Xin *, L. Gao \\ School of Civil Engineering, Beijing Jiaotong University, Beijing 100044, China
}

\section{A R T I C L E I N F O}

\section{Article history:}

Received 13 April 2010

Received in revised form

19 October 2010

Accepted 20 November 2010

Handling Editor: L.G. Tham

Available online 16 December 2010

\begin{abstract}
A B S T R A C T
In this paper, the problem of vibration transmission from slab track structures into bridge is studied by theoretical analysis. A vehicle-track-bridge coupling system dynamics model is established based on a multibody dynamics theory and a finite element method. The system model consists of vehicle model, track-bridge model and wheel/rail interaction model. The vehicle model is established based on the multibody dynamics theory, and the tack-bridge model is established by the finite element method. The vehicle model and track-bridge model are coupled through wheel/rail interaction model, and the track irregularities are included. The system dynamic responses are calculated, and the effectiveness of elastic materials in vibration reducing is discussed. The results demonstrate that elastic materials like slab mat layer inserted between slab track and bridge can reduce vibration transmitted from track into the bridge. Some suggestions for the design and application of slab mat are provided in the end of the paper.
\end{abstract}

(c) 2010 Elsevier Ltd. All rights reserved.

\section{Introduction}

With large scale construction of high-speed railway in China, railway station buildings such as waiting halls and station platforms are placed on or under bridge inevitably, the noise and vibration problems become more and more serious. For reducing the vibration of bridge and surrounding buildings, vibration control measures must be taken. Since the railway station buildings vibration is mainly transmitted from railway track induced by running vehicle, reducing track vibration is an effective method. To solve this problem, elastic materials are gradually applied in the construction of high speed railway in China.

Slab track structures are widely applied in China high speed railway, which advantages are long service life, low cost and good control of track irregularity, etc. For slab track, inserting elastic materials like slab mat layer between the track and the foundation is an effective method for vibration isolation. It is a practical method which is widely used in urban rail transportation system of floating slab track to reduce vibration transmitted into the soil and surrounding buildings. Whether the method can be used in high speed railway? Comparing with urban rail transportation system, high speed railway has its own characteristics, thus the limits to its application are posed by heavy axle load, high speed, track laying on the bridge and other differences. Dynamic simulation is a useful and effective tool for solving this problem.

A lot of research work has been performed in this field and sophisticated analytical models increasingly have been developed by researchers worldly. The fundamental theories of interaction between trains and railway track or bridge

\footnotetext{
* Corresponding author. Tel.: +861051687243.

E-mail address: xt1010@163.com (T. Xin).
} 
structures have been published by a lot of researchers including Frýba [1], Li and Su [2], Yau and Yang [3], Ju and Lin [4], Zhai [5] and Xia [6].

The dynamic behavior of railway bridges caused by high speed trains has been an important topic of great interest in the field of civil engineering. Great efforts have been continuously spent to the subject of dynamic interaction of trains and bridges. Xia et al. [7] adopted a three-dimensional finite element model for dynamic analysis of a long suspension bridge. Xia et al. [8] investigated the resonance mechanism and conditions of train-bridge system through theoretical derivations, numerical simulations and experimental data analysis. Zhang et al. [9] studied the dynamic interaction between high-speed train and simply supported girders by theoretical analysis and field experiment. Yau et al. [10] studied the dynamic response of bridge girders with elastic bearings to moving train loads using an analytical approach. Yang et al. [11] explained the mechanism involved in the phenomena of resonance and cancellation in the train-induced vibrations of railway bridges with elastic bearings. Yang et al. [12] studied the dynamic interaction between a moving vehicle and the sustaining bridge. Zhang et al. [13] developed a space model for train carriages used in dynamic analysis of train-bridge interaction. Lee and Kim [14] developed a three-dimensional model for analyzing the dynamic interaction that occurs between high-speed trains and bridges.

Most of models above are focused on vehicle or bridge dynamics behavior, less attention are paid on track vibration, especially on the slab track on bridge in high speed railway. This paper mainly discusses the slab track vibration problem, in order to find effective method to reduce slab track vibration into surrounding environments like bridge.

To attenuate disturbance in residential buildings located along metropolitan railway lines, special types of track bedding have been designed, based on fixation of the rail on floating slabs resting on elastic materials. Castellani et al. [15] reported that compared to ballast track, floating slab offers the possibility to fit the track to the soil conditions and train excitation. They presented an interpretative model of dynamic behavior of electrometric pads and made effort to example a mathematical model for elastic materials. The floating slab tracks have been widely used to control vibration from underground trains in urban rail transit. Cui and Chew [16] investigated the effectiveness of a floating slab track system to stationary harmonic loads and moving harmonic loads by using the reacceptance method. Hunt [17], and Hussein and Hunt [18] discussed modelling of floating slab tracks on rigid foundations; the Fourier transformation method was used to calculate track displacements under an oscillating moving load. Xin et al. [19] presented a train-track coupling dynamics model to analyze the vibration characteristics of floating slab track in time domain.

With respect to slab track on bridge, a vehicle-track-bridge coupling system dynamics model was established to analyze whether floating slab solution could fit high speed railway.

\section{System model}

In this paper, the system model consists of vehicle model with two suspensions, track-bridge model (rail, slab, bridge and accessory structures), and wheel/rail interaction model. The vehicle model is established based on multibody dynamics theory and the tack-bridge model by finite element method. The vehicle model and track-bridge model are coupled through wheel/rail interaction model with track irregularities included.

\subsection{Vehicle model}

According to general vehicle structure used in China, a 4-axle railway vehicle with two suspensions is established. The following assumptions are adopted in the vehicle model as those used in most researches [5,6,19]:

(1) The vehicle running on the bridge at a constant speed and the system vibration in longitudinal direction is not considered. As the research focuses on propagation of vertical vibration, lateral vibration is not considered although a spatial vehicle model is easy to establish.

(2) The vehicle is modelled as a multirigid body system composed of car body, bogie frames and wheel-sets. The car body, bogies and wheel-sets are regarded as rigid components connected by spring-dampers each other, neglecting their elastic deformation during vibration.

(3) The connections between a bogie and a wheel-set are characterized by spring-dampers, named the first suspension system. The connections between the car body and a bogie are characterized by spring-dampers, named the second suspension system. The springs in the vehicle elements are all with linear property, and the dampers are with viscous property.

(4) In coordinate system of model, $Z$ is vertically downwards, $X$ is along the rail and $Y$ is perpendicular to the rail in horizontal plane. The vehicle model has 17 dof (degree of freedom). Concretely speaking, the car body has 3 dof in direction of $Z$, rotating $Z$ and rotating $Y$ (named floating, pitching, and rolling vibration), so do the two bogie frames. Each wheel-set owns 2 dof, whose pitching vibration is not taken into account. 


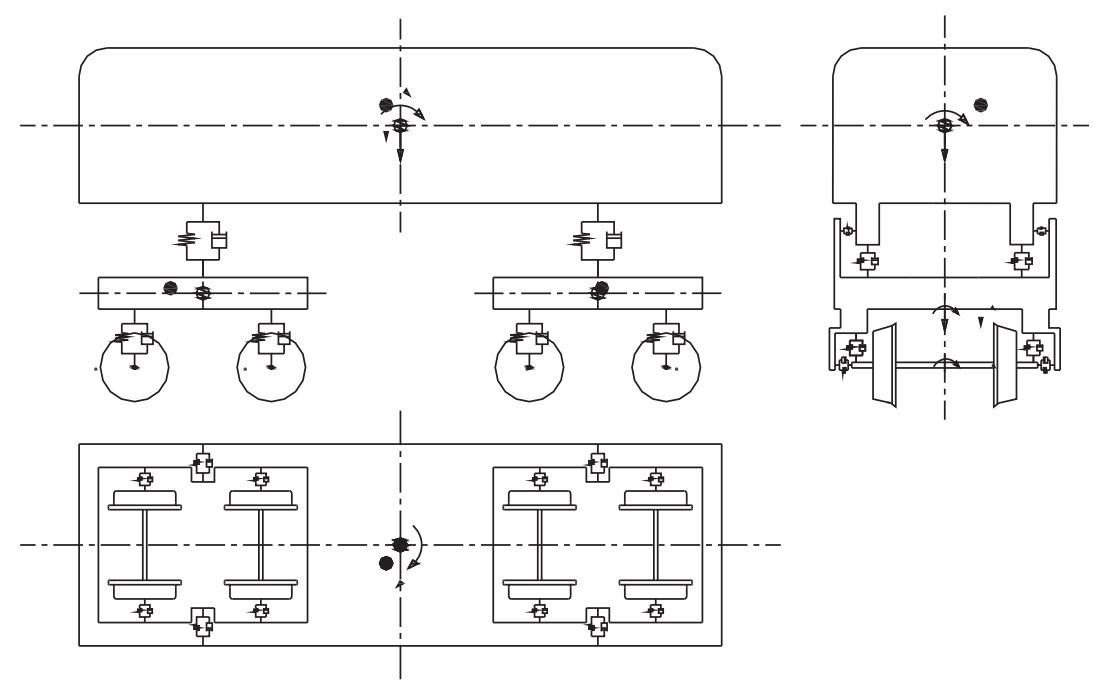

Fig. 1. Vehicle model.

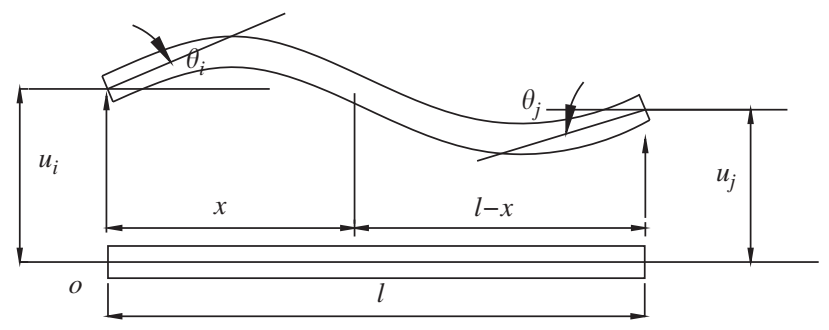

Fig. 2. Beam element.

\subsection{Track-bridge model}

The track-bridge model is modelled as two parts, the track and the bridge.

The track is composed of the rail, the slab and slab mat layer. The rail is modelled as point supporting Euler beam elements. The deformation of each beam element is defined by the degree of freedom at the end node $i$ and node $j$. The displacement vector $\delta_{b}^{e}$ of the beam are appeared as

$$
\delta_{b}^{e}=\left[u_{i}, \theta_{i}, u_{j}, \theta_{j}\right]^{T}
$$

where $u_{i}$ and $u_{j}$ are the translational displacement, $\theta_{i}$ and $\theta_{j}$ are the rotational displacement of nodes $i$ and $j$, respectively. The beam element is shown in Fig. 2.

The slab is modelled as elastic thin plate elements in vertical direction, accounting for both bending deformation, whose mats are assumed as a set of distributed, independent liner springs and dampers. For the elastic thin plate element, the deformation is defined by the degree of freedom at the end node $i, j, k$ and $l$. The displacement vector $\delta_{p}^{e}$ of the beam appear as

$$
\delta_{p}^{e}=\left[\begin{array}{lllllllllllll}
w_{i} & \theta_{x i} & \theta_{y i} & w_{j} & \theta_{x j} & \theta_{y j} & w_{k} & \theta_{x k} & \theta_{y k} & w_{l} & \theta_{x l} & \theta_{y l}
\end{array}\right]^{T}
$$

where each node has $3 \operatorname{dof}\left(w, \theta_{x}, \theta_{y}\right) . w$ is the translational displacement in the $Z$ direction, and $\theta_{x}$ and $\theta_{y}$ are the displacements in the rotating $X$ and $Y$ directions. The elastic thin plate element is shown in Fig. 3.

The rail and slab are connected by several fasteners which can be modelled as springs and dampers. The springs are with linear property, and the dampers are with viscous property.

The bridge body is also modelled as Euler beam element which is constrained in the position of bridge piers. When the vehicle passed from the bridge, the force transmitted into bridge through the track. Fig. 4 shows the model of the track and bridge.

\subsection{Wheel/rail interaction model}

The interaction between wheels and track is carried out by the wheel/rail contact. The wheel/rail contact geometrical parameters are computed in the analysis of wheel/rail interaction. The normal force of wheel/rail contact is described by 


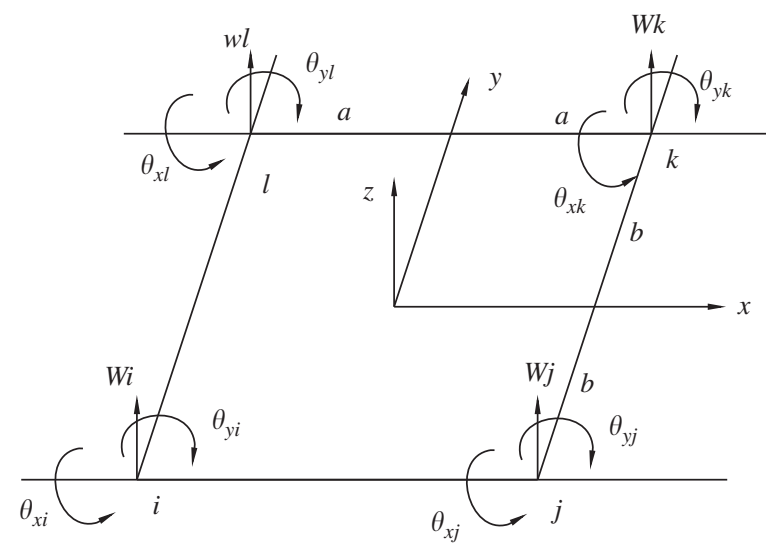

Fig. 3. Elastic thin plate element.

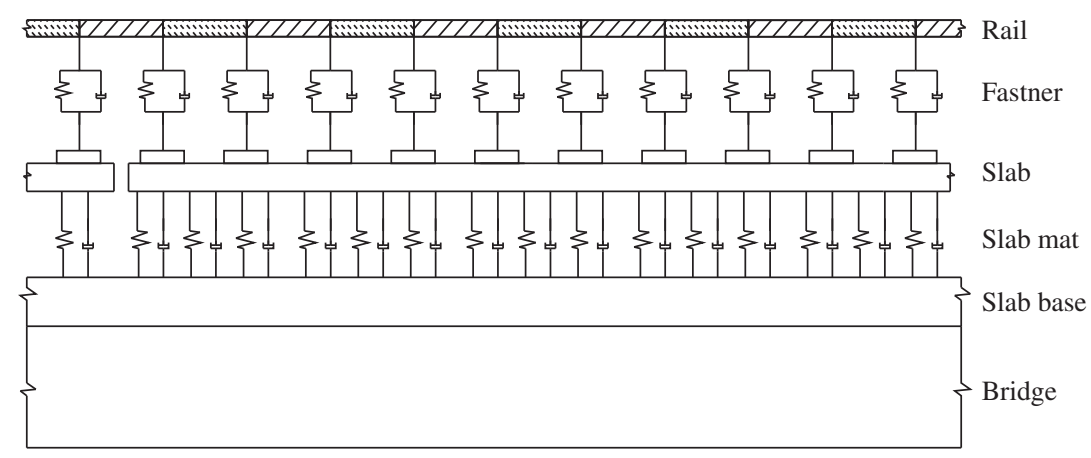

Fig. 4. Track-bridge model.

Hertz nonlinear elastic contact theory:

$$
P(t)=(\Delta Z(t) / G)^{3 / 2}
$$

where $G$ is the contact coefficient and $\Delta Z(t)$ is the elastic penetration.

The penetration between wheel and rail is determined by the relative displacement of wheel and rail, including static compression value of wheel/rail contact point:

$$
\Delta Z(t)=Z_{w i}(t)-Z_{r i}(x, t)-\eta(x)
$$

where $Z_{w i}(t)$ is the vertical displacement of wheel $i$ at time $t, Z_{r i}(x, t)$ is the vertical displacement of rail at the relevant contact point and $\eta(x)$ is the track vertical irregularity. It should be pointed out that when $\Delta Z(t)$ is less than zero, the wheel/rail force is equal zero.

The track irregularities are input as excitation of the whole vibration system. For engineering application, track irregularities can be approximately regarded as stationary stochastic process which can be simulated by numerical methods. The wheel hunting is usually omitted due to weak effect. As mentioned above, the research focused on propagation of vertical vibration, so lateral vibration is not considered and only vertical profile irregularity is taken into account. Track vertical profile irregularity is applied to both rails. The track vertical profile irregularity can be generated by inverse Fourier transform as follows:

$$
\xi(x)=\sqrt{2} \sum_{k=1}^{N} \sqrt{S\left(\omega_{k}\right) \Delta \omega} \cos \left(\omega_{k} x+\phi_{k}\right)
$$

where $\omega_{k}$ is a circular frequency with interval, $S\left(\omega_{k}\right)$ is power spectral density of track irregularities, $\phi_{k}$ is a random phase angle uniformly distribute from 0 to $2 \pi, \Delta \omega$ is frequency increment and $N$ is the total number of frequency increments range from the lower frequency limit $\omega_{l}$ to the upper frequency limit $\omega_{u}$, so $\Delta \omega=\left(\omega_{u}-\omega_{l}\right) / N$.

The PSD function of track irregularities used in the case study is

$$
S_{v}(\Omega)=\frac{A_{v} \Omega_{c}^{2}}{\left(\Omega^{2}+\Omega_{r}^{2}\right)\left(\Omega^{2}+\Omega_{c}^{2}\right)}
$$




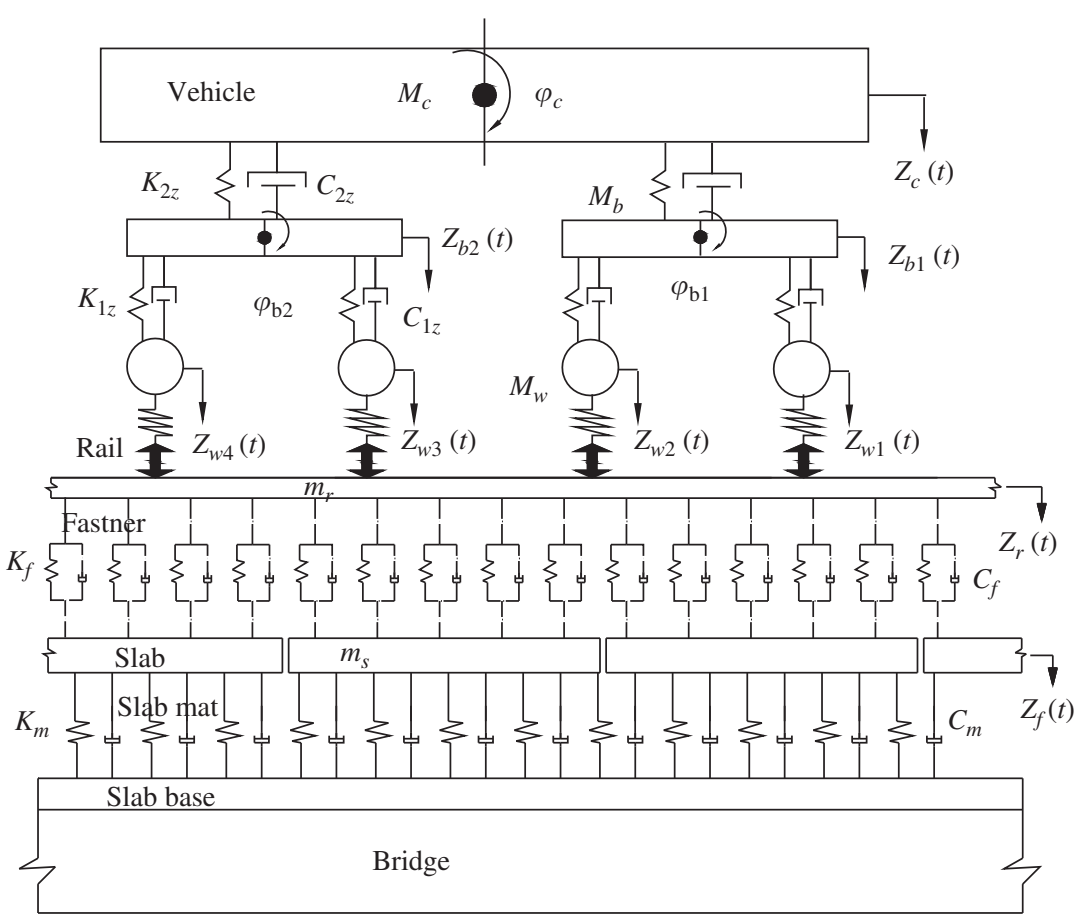

Fig. 5. System model.

where $A_{v}$ is constant of roughness, $\Omega$ is spatial frequency, $\Omega_{r}$ and $\Omega_{c}$ are cutoff frequency. For high speed railway whose running speed exceeds $250 \mathrm{~km} / \mathrm{h}, A_{v}=4.032 \times 10^{-7} \mathrm{~m}^{2} \mathrm{rad} / \mathrm{m}, \Omega_{c}=0.8246 \mathrm{rad} / \mathrm{m}, \Omega_{r}=0.0206 \mathrm{rad} / \mathrm{m}$.

\subsection{Vibration equations and simulation program}

By assuming that the vibration amplitude of the vehicle, the track and the bridge is small and with the equilibrium conditions used, the coupled equations of motion for the vehicle-track-bridge system can then be derived as follows:

$$
\left[\begin{array}{lll}
M_{v v} & 0 & 0 \\
0 & M_{t t} & 0 \\
0 & 0 & M_{b b}
\end{array}\right]\left\{\begin{array}{l}
\ddot{\delta}_{v} \\
\ddot{\delta}_{t} \\
\ddot{\delta}_{b}
\end{array}\right\}+\left[\begin{array}{lll}
C_{v v} & C_{v t} & 0 \\
C_{t v} & C_{t t} & C_{t b} \\
0 & C_{b t} & C_{b b}
\end{array}\right]\left\{\begin{array}{l}
\dot{\delta}_{v} \\
\dot{\delta}_{t} \\
\dot{\delta}_{b}
\end{array}\right\}+\left[\begin{array}{lll}
K_{v v} & K_{v t} & 0 \\
K_{t v} & K_{t t} & K_{t b} \\
0 & K_{b t} & K_{b b}
\end{array}\right]\left\{\begin{array}{l}
\delta_{v} \\
\delta_{t} \\
\delta_{b}
\end{array}\right\}=\left\{\begin{array}{l}
P_{v} \\
P_{t} \\
P_{b}
\end{array}\right\}
$$

where $[M],[C]$ and $[K]$ are mass matrix, damping matrix and stiffness matrix of the whole system, $\{\delta\},\{\dot{\delta}\},\{\ddot{\delta}\}$ are displacement vector, velocity vector and acceleration vector, $\{P\}$ is the load vector, and the subscripts $v, t$ and $b$ represent the vehicle, track and bridge, respectively. Newmark- $\beta$ method is used to solve the equations.

According to the modelling method above, the simulation program VTBDSS (Vehicle-Track-Bridge Dynamic Simulation System) is coded in FORTRAN language. The system model is shown in Fig. 5.

\section{Case study}

Vibration reducing effectiveness will be analyzed by the following steps: first, natural frequency of the slab track with and without slab mat layer is gathered. Two methods are used in the study, one is frequency sweeping method, and the other is impact method, respectively. Second, the vibration reducing effect is analyzed. The vehicle-track-bridge coupling system dynamics model is used. At last, slab mat layer's influence on the system dynamic responses is studied, using the coupling system dynamics model established in this paper.

\subsection{System parameters}

The vehicle main parameters used in the case study are shown in Table 1, and main parameters of the slab track and bridge are shown in Table 2, all these parameters are corresponding to real vehicle and bridge situation.

The station is located on concrete continuous beam bridge $(32.7+32.7+48+32.7+32.7)$, and the total length of the continuous beam bridge is $178.8 \mathrm{~m}$. The dimension and layout of slab track with slab mat layer is shown in Fig. 6, and bridge sketch is shown in Fig. 7. For slab track without slab mat layer, the slab is connected with the slab base directly. 
Table 1

Main parameters of the vehicle.

\begin{tabular}{|c|c|c|c|}
\hline Parameters & Notation & Unit & Value \\
\hline Mass of car body & $m_{c}$ & $\mathrm{~kg}$ & 42,400 \\
\hline Mass of bogie frame & $m_{b}$ & $\mathrm{~kg}$ & 3400 \\
\hline Mass of wheel-set & $m_{w}$ & $\mathrm{~kg}$ & 2200 \\
\hline Moment of inertia of car body frame about the $x$-axis & $I_{C X}$ & $\mathrm{~kg} \mathrm{~m}^{2}$ & 101,500 \\
\hline Moment of inertia of car body frame about the $y$-axis & $I_{c y}$ & $\mathrm{~kg} \mathrm{~m} \mathrm{~m}^{2}$ & $2,740,000$ \\
\hline Moment of inertia of bogie frame about the $x$-axis & $I_{b x}$ & $\mathrm{~kg} \mathrm{~m}^{2}$ & 3200 \\
\hline Moment of inertia of bogie frame about the $y$-axis & $I_{b y}$ & $\mathrm{~kg} \mathrm{~m}^{2}$ & 7200 \\
\hline Moment of inertia of wheel-set about the $x$-axis & $I_{w x}$ & $\mathrm{~kg} \mathrm{~m}^{2}$ & 1630 \\
\hline Vertical stiffness of primary suspension & $K_{1 z}$ & $\mathrm{MN} / \mathrm{m}$ & 1.04 \\
\hline Vertical damping of primary suspension & $C_{1 z}$ & $\mathrm{kN} \mathrm{s} / \mathrm{m}$ & 5.0 \\
\hline Vertical stiffness of secondary suspension & $K_{2 z}$ & $\mathrm{MN} / \mathrm{m}$ & 0.40 \\
\hline Vertical damping of secondary suspension & $C_{2 z}$ & $\mathrm{kN} \mathrm{s} / \mathrm{m}$ & 6.0 \\
\hline Radius of wheel & $R_{w}$ & $\mathrm{~m}$ & 0.4575 \\
\hline Full length & $l$ & $\mathrm{~m}$ & 26.3 \\
\hline Half-distance between two bogies & $d_{b}$ & $\mathrm{~m}$ & 9.0 \\
\hline Half-distance between wheel-sets & $d_{w}$ & $\mathrm{~m}$ & 1.25 \\
\hline Half-distance between rolling circularity & $d_{r}$ & $\mathrm{~m}$ & 0.748 \\
\hline Half-distance between first suspension system & $d_{1}$ & $\mathrm{~m}$ & 1.025 \\
\hline Half-distance between second suspension system & $d_{2}$ & $\mathrm{~m}$ & 1.100 \\
\hline Distance between car body and second suspension system & $h_{1}$ & $\mathrm{~m}$ & 1.20 \\
\hline Distance between second suspension system and bogie & $h_{2}$ & $\mathrm{~m}$ & -0.02 \\
\hline Distance between bogie and wheel-set & $h_{3}$ & $\mathrm{~m}$ & 0.13 \\
\hline
\end{tabular}

Table 2

Main parameters of the track and bridge.

\begin{tabular}{|c|c|c|c|}
\hline Parameters & Notation & Unit & Value \\
\hline Mass of rail beam per unit length & $m_{r}$ & $\mathrm{~kg}$ & 60.64 \\
\hline Area of rail section & $A_{r}$ & $\mathrm{~cm}^{2}$ & 77.45 \\
\hline Elastic modulus of rail & $E_{r}$ & $\mathrm{MPa}$ & 205,900 \\
\hline Rail moment of inertia about the $z$-axis & $I_{r z}$ & $\mathrm{~cm}^{4}$ & 3217 \\
\hline Rail pad stiffness & $K_{p}$ & $\mathrm{MN} / \mathrm{m}$ & 60.0 \\
\hline Rail pad damping & $C_{p}$ & $\mathrm{kN} \mathrm{s} / \mathrm{m}$ & 27.0 \\
\hline Mass of slab per unit length & $m_{s}$ & $\mathrm{~kg}$ & 1651.6 \\
\hline Elastic modulus of slab & $E_{s}$ & $\mathrm{MPa}$ & 32,500 \\
\hline Density of bridge body & $\rho_{b}$ & $\mathrm{~kg} / \mathrm{m}^{3}$ & 2500 \\
\hline Elastic modulus of bridge body & $E_{b}$ & $\mathrm{MPa}$ & 34,500 \\
\hline Area of bridge body section & $A_{b}$ & $\mathrm{~m}^{2}$ & 8.24 \\
\hline Bridge body moment of inertia about the $z$-axis & $I_{b z}$ & $\mathrm{~m}^{4}$ & 12.0 \\
\hline
\end{tabular}

In the model, the rail and the bridge are with the same length, and both ends are free. The vehicle runs from the side span to the middle span and then to another side span. The simulation results are from the mid-span section of the middle span, which is the major span (the third span, with a length of $48 \mathrm{~m}$ ) of the bridge. And what's more, in order to reduce the influence of the boundary condition of the model to the simulation results, the distances between the vehicle and the end of the bridge are long enough at both the start position and the stop position.

\subsection{Natural frequency determination}

Two methods are used here to mutual verification. Slab mat stiffness $K_{m}=20 \mathrm{MN} / \mathrm{m}^{3}$ here:

(a) Frequency sweeping method: single point periodic load is used. The exciting load function is as follows:

$$
P=P_{0} \sin \left(2 \pi f_{i} t\right)
$$

where $P_{0}$ is the amplitude, and $f_{i}$ is exciting frequency. In order to get natural frequency quickly and accurately, rough sweeping and accurate sweeping are adopted in succession. The acceleration of the slab is obtained.

(b) Impact method: as load impacts on the slab in instant, the acceleration of the slab is obtained. Then the acceleration is transformed by Fourier transformation.

The results calculated by these two methods are shown in Fig. 8. 
(a)

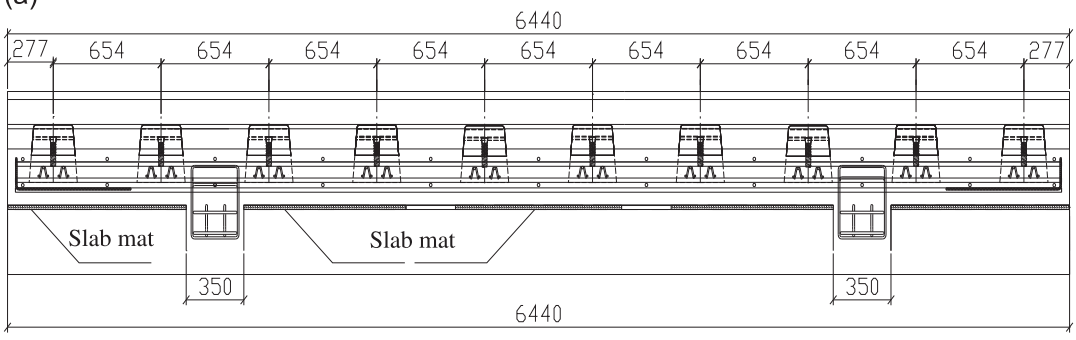

(b)

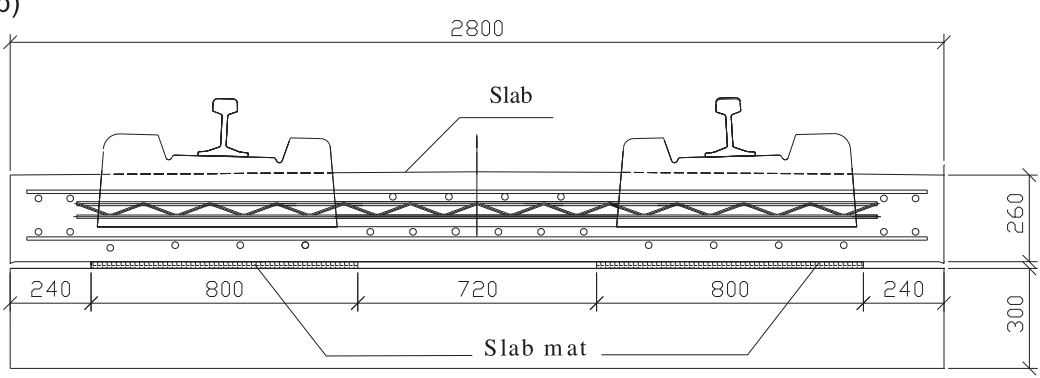

Fig. 6. Track layout: (a) longitudinal section and (b) lateral section.

$32.7+32.7+48+32.7+32.7 \mathrm{~m}$ continuous beam bridge

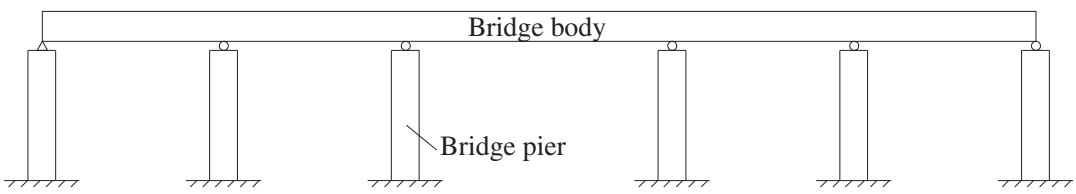

Fig. 7. Sketch of continuous beam bridge.

In order to compare the results obtained by the two methods above, the amplitude are both divided by the maximum peak value. From Fig. 8, the peak value of acceleration of the slab appears at almost the same frequency $f_{0}$, about $23.5 \mathrm{~Hz}$. According to vibration isolation principle of single degree of freedom, isolation system can exert its function while the exciting frequency is more than $\sqrt{2} f_{0}$, about $33.2 \mathrm{~Hz}$ for the slab with slab mat layer.

\subsection{Vibration reducing effect analysis}

Two types of slab track (with and without slab mat layer) are compared below. Running speed is $350 \mathrm{~km} / \mathrm{h}$ for main line, and $80 \mathrm{~km} / \mathrm{h}$ for station line. Slab mat stiffness $K_{m}=20 \mathrm{MN} / \mathrm{m}^{3}$ here. It should be pointed out that, the slab mat layer is mainly designed for train's high speed passing, and train's low speed passing is incidentally taken in consideration. Although the track vertical profile irregularity is for train speeds higher than $250 \mathrm{~km} / \mathrm{h}$, but for determining vibration reducing effect of slab mat under different train speeds, so except for the slab mat stiffness, the rest parameters are the same. For studying the vibration reducing effect, the bridge acceleration is chosen as the index to demonstrate vibration reducing effects. All the simulation results presented in this paper are from mid-span section of bridge:

(a) Main line: the result in time domain is shown in Fig. 9(a), and the result in frequency domain (1/3 octave) is shown in Fig. 9(b).

From Fig. 9(a), it can be seen that, comparing with the track without slab mat layer, the track with slab mat layer can reduce bridge acceleration greatly, from 3.0 to $0.8 \mathrm{~m} / \mathrm{s}^{2}$, about 73.3\%. From Fig. 9(b), the bridge acceleration level is reduced by $23 \mathrm{~dB}$ at most in high frequency zone. The intersection point between the curves is corresponding to $31.5 \mathrm{~Hz}$, which is approximately equal to the results calculated by the two methods above. The reason for the great vibration reduction effects is that the slab mat layer has a very good effect of vibration isolation in the range of frequency larger than $31.5 \mathrm{~Hz}$ (about $\sqrt{2} f_{0}$ ).

(b) Station line: the result in time domain is shown in Fig. 10(a), and the result in frequency domain (1/3 octave) is shown in Fig. 10(b).

From Fig. 10(a), it can be seen that, comparing with the track without slab mat layer, the bridge acceleration of track with slab mat layer is greatly reduced, from 0.53 to $0.15 \mathrm{~m} / \mathrm{s}^{2}$, about $71.7 \%$. From Fig. 10 (b), the bridge acceleration level can be 


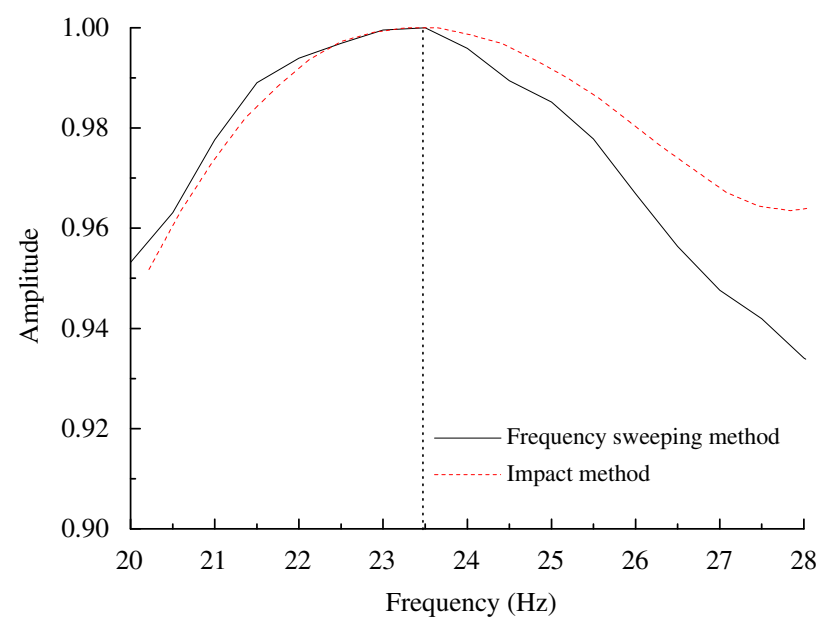

Fig. 8. Natural frequency determination.
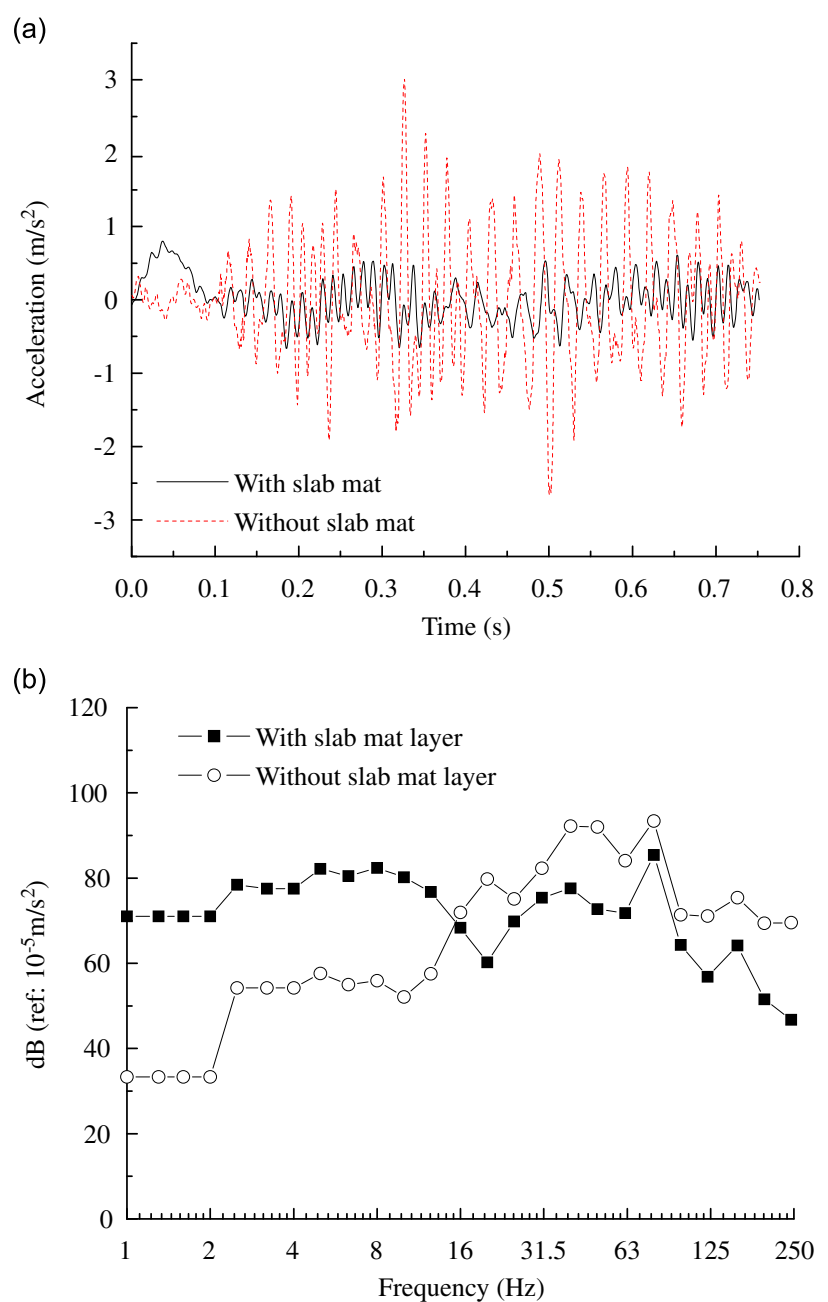

Fig. 9. Bridge acceleration of main line: (a) time history curve and (b) 1/3 octave curve.

reduced by $26 \mathrm{~dB}$ in high frequency zone. The intersection point between the curves is corresponding to $20 \mathrm{~Hz}$, which is less than the results calculated above. However, the acceleration decreased in the station line is almost the same as that in the main line. Since the running speed over station line is small, the vibration levels are smaller than that in main lines. 

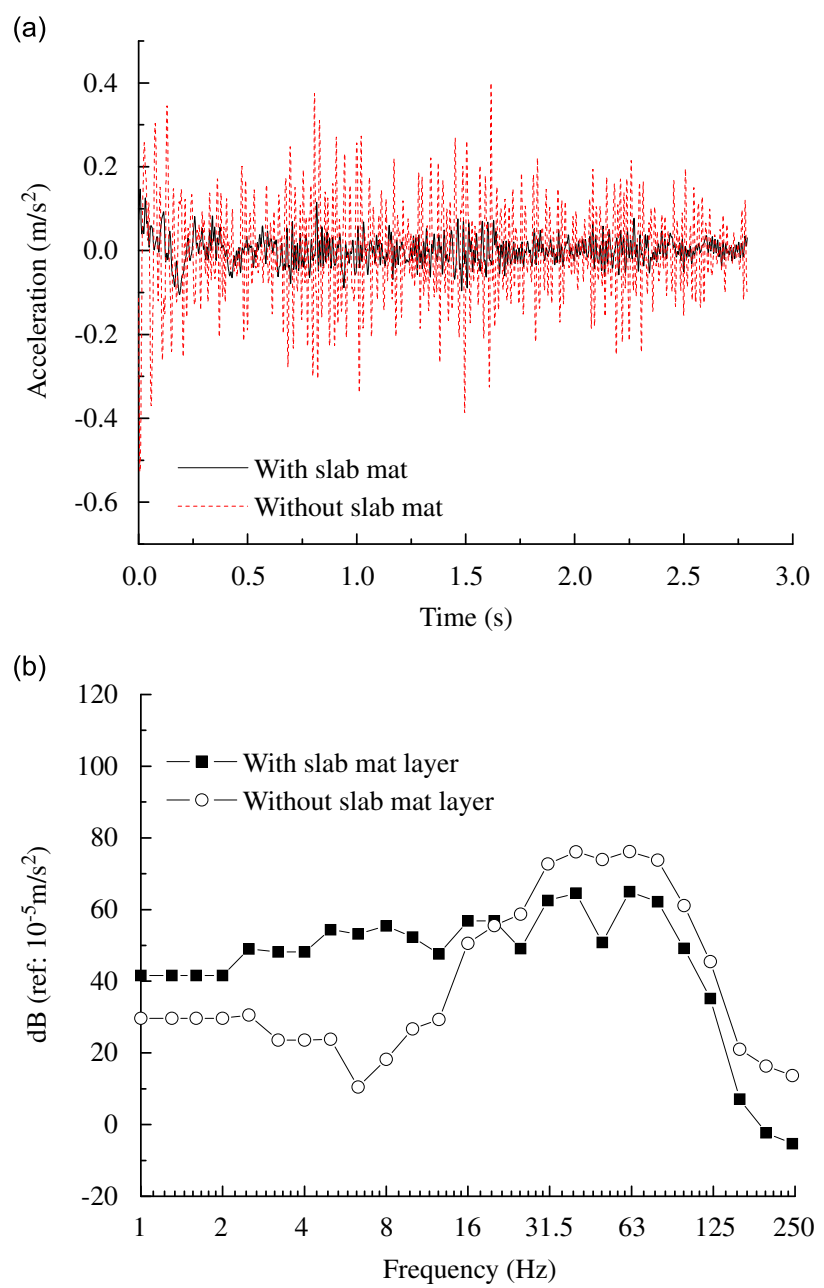

Fig. 10. Bridge acceleration of station line: (a) time history curve and (b) $1 / 3$ octave curve.

Figs. 9(b) and 10(b) show a great increase in vibration levels with the mat layer for frequencies below around $20 \mathrm{~Hz}$. Similar to the application of floating slab track, the application of mat layer enlarge the vibration of bridge in the range of low frequencies. However, considering the excellent effect of reducing vibration transmitted from slab track into bridge, as analyzed above vibration reduced for over $70 \%$ on both main line and station line, it can still be concluded that applying mat layer between slab track and bridge is an available and reasonable measure for bridge structures which are not sensitive to low-frequency vibration. This is because even though low-frequency vibration is important for environmental vibration, high-frequency vibrations are major vibration forms for track structures of high-speed railway.

However, for structures and regions that low-frequency vibration should be strictly controlled, the disadvantages of mat layer to low-frequency vibration should be considered seriously, not to take this measure of vibration reduction or taking other measures during the process of vibration transmission from bridge to neighbor buildings of the station.

According to research above, vibrations of bridge transmitted from track are greatly reduced when the slab mat layer is applied. Thus it can be concluded that the slab mat layer performs well in high speed railway line, both in the main line and in the station line.

\subsection{Slab mat stiffness influences}

Stiffness is the most important parameter on vibration reducing function for elastic materials. The slab mat layer's influences on the system dynamic responses are studied, by varying stiffness from a lower value to a higher value. Since almost the same vibration reducing effectiveness are as analyzed above, only system dynamic responses of main line condition are calculated and shown in Table 3.

It can be seen that slab mat stiffness has great influences on rail and slab displacements which are shown in Figs. 11 and 12 . It affects less on wheel/rail force and bridge displacements. The accelerations of rail and slab are also changing with slab mat 
Table 3

dynamic response under different slab mat stiffness.

\begin{tabular}{|c|c|c|c|c|c|c|c|}
\hline $\begin{array}{l}\text { Slab mat } \\
\text { stiffness } \\
\left(\mathrm{MN} / \mathrm{m}^{3}\right)\end{array}$ & $\begin{array}{l}\text { Wheel/rail } \\
\text { force }(\mathrm{kN})\end{array}$ & $\begin{array}{l}\text { Rail } \\
\text { acceleration } \\
\left(\mathrm{m} / \mathrm{s}^{2}\right)\end{array}$ & $\begin{array}{l}\text { Rail } \\
\text { displacement } \\
(\mathrm{mm})\end{array}$ & $\begin{array}{l}\text { Slab } \\
\text { acceleration } \\
\left(\mathrm{m} / \mathrm{s}^{2}\right)\end{array}$ & $\begin{array}{l}\text { Slab } \\
\text { displacement } \\
(\mathrm{mm})\end{array}$ & $\begin{array}{l}\text { Bridge } \\
\text { acceleration } \\
\left(\mathrm{m} / \mathrm{s}^{2}\right)\end{array}$ & $\begin{array}{l}\text { Bridge } \\
\text { displacement } \\
(\mathrm{mm})\end{array}$ \\
\hline 10 & 124.05 & 136.28 & 8.13 & 38.61 & 7.29 & 0.79 & 2.60 \\
\hline 20 & 123.29 & 128.48 & 5.48 & 35.89 & 4.92 & 0.80 & 2.60 \\
\hline 30 & 122.59 & 125.51 & 4.76 & 40.22 & 4.02 & 0.82 & 2.60 \\
\hline 40 & 121.11 & 125.13 & 4.38 & 43.70 & 3.64 & 0.97 & 2.59 \\
\hline 50 & 119.94 & 124.14 & 4.11 & 45.40 & 3.46 & 1.14 & 2.58 \\
\hline 60 & 119.70 & 122.63 & 3.95 & 45.41 & 3.35 & 1.31 & 2.58 \\
\hline 70 & 119.84 & 121.62 & 3.86 & 47.25 & 3.27 & 1.48 & 2.58 \\
\hline 80 & 120.37 & 120.42 & 3.80 & 52.40 & 3.20 & 1.65 & 2.58 \\
\hline 90 & 120.80 & 118.19 & 3.74 & 56.74 & 3.13 & 1.89 & 2.58 \\
\hline 100 & 121.08 & 114.58 & 3.68 & 59.66 & 3.07 & 2.10 & 2.57 \\
\hline 110 & 121.73 & 109.71 & 3.62 & 61.84 & 3.01 & 2.22 & 2.57 \\
\hline 120 & 125.42 & 105.22 & 3.57 & 63.67 & 2.96 & 2.34 & 2.57 \\
\hline 130 & 128.41 & 102.78 & 3.52 & 64.91 & 2.92 & 2.50 & 2.57 \\
\hline 140 & 129.57 & 100.70 & 3.48 & 65.11 & 2.88 & 2.63 & 2.57 \\
\hline 150 & 128.90 & 99.40 & 3.47 & 63.95 & 2.85 & 2.72 & 2.57 \\
\hline
\end{tabular}

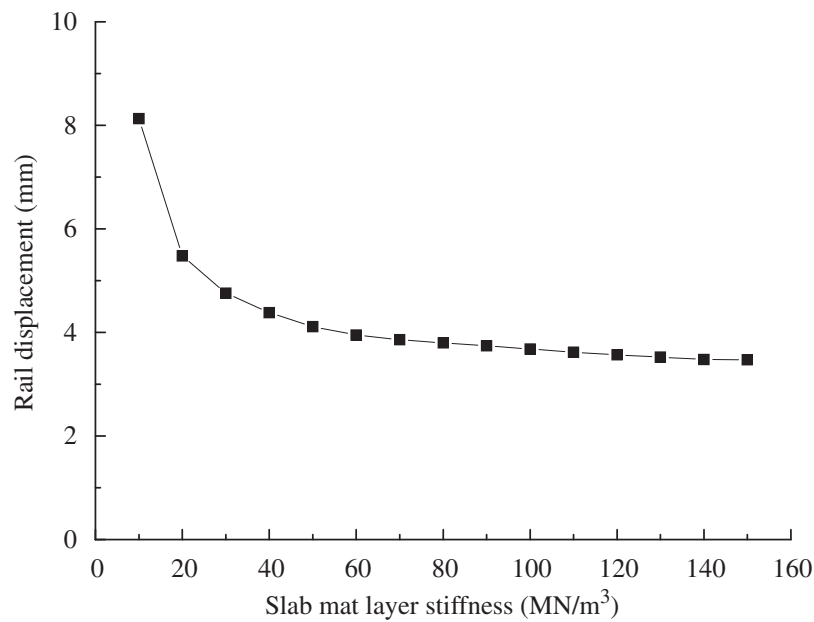

Fig. 11. Relationship curve between rail displacement and slab mat stiffness.

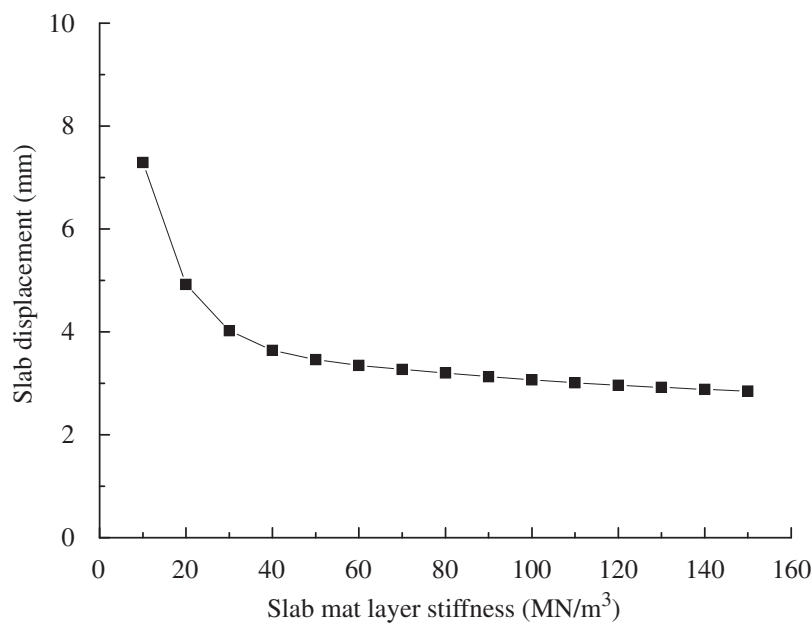

Fig. 12. Relationship curve between slab displacements and slab mat stiffness. 


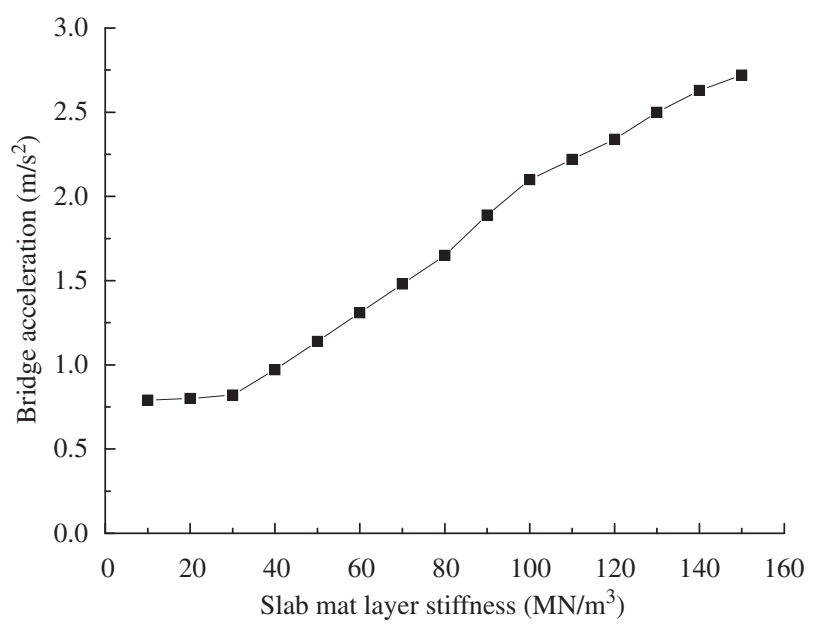

Fig. 13. Relationship curve between bridge acceleration and slab mat stiffness.

stiffness. For the parameters listed above, rail acceleration is decreasing with increase of slab mat stiffness, and slab acceleration is increasing with increase of slab mat stiffness.

However, the changing extent of rail acceleration and slab acceleration of are less than that of bridge acceleration. The relationship curve between bridge acceleration and slab mat stiffness is shown in Fig. 13. It can be seen that with slab mat stiffness changing from 10 to $150 \mathrm{MN} / \mathrm{m}^{3}$, bridge acceleration jumped from 0.79 to $2.72 \mathrm{~m} / \mathrm{s}^{2}$. Slab mat of lower stiffness is very effective in reducing vibration of bridge than that of higher stiffness. However if the stiffness is too low, the displacement of rail and slab will increase greatly, which will do harm to the track life and track smoothness. Thus from the view of the whole system, slab mat stiffness should be restricted on a reasonable scale. For this case study, slab mat stiffness $K_{m}=20-40 \mathrm{MN} / \mathrm{m}^{3}$ is recommended.

\section{Conclusions}

This paper deals with modelling method of vehicle-track-bridge and vibration reducing effectiveness of slab mat layer in high speed railway. Some conclusions can be drawn below.

The track with slab mat layer lead to much smaller vibration on the bridge. Slab mat layer is useful for reducing vibration transmitted from track into bridge in high speed railway. Similar to the floating slab track, the vibrations in low-frequency range are enlarged. Thus, in regions that low-frequency vibration are required strictly controlled, it should be seriously considered not to take this measure or taking other measures suitable for low-frequency vibration reduction during the process of vibration transmission from bridge to neighbor buildings of railway stations.

Slab mat layer affects less on wheel/rail force and bridge displacements than on rail displacement and slab displacement, and it also results in rail and slab acceleration variations.

Slab mat layer poses dominant influence to bridge acceleration. Slab mat layer of low stiffness is more effective than that of high stiffness. However it is not equal to the lowest is the best. Too low stiffness of slab mat layer will increase the displacements of rail and slab, thereby deteriorate track life and smoothness.

For the case study in this paper, slab mat layer stiffness of $20-40 \mathrm{MN} / \mathrm{m}^{3}$ is recommended. It should be noted that all the conclusions made in this paper remain strictly valid only for the particular model, with parameters and assumptions adopted in this paper.

\section{Acknowledgement}

This study was sponsored by the National Natural Science Foundation of China (50878018).

\section{References}

[1] L. Frýba, Vibration of Solids and Structures under Moving Loads, Thomas Telford, London, 1999.

[2] J.Z. Li, M.B. Su, The resonant vibration for a simply supported girder bridge under high-speed trains, Journal of Sound and Vibration 224 (1999) 897-915.

[3] J.D. Yau, Y.B. Yang, Theory of Vehicle-Bridge Interaction for High Speed Railway, DNE Publisher, Taipei, 2002.

[4] S.H. Ju, H.T. Lin, Resonance characteristics of high-speed trains passing simply supported bridges, Journal of Sound and Vibration 267 (2003) $1127-1141$.

[5] W.M. Zhai, Vehicle-Track Coupling Dynamics, China Railway Publishing House, Beijing, 2002.

[6] H. Xia, Dynamic Interaction between Vehicles and Structures, Science Press, Beijing, 2005.

[7] H. Xia, Y.L. Xu, T.H.T. Chan, Dynamic interaction of long suspension bridges with running trains, Journal of Sound and Vibration 237 (2000) $263-280$.

[8] H. Xia, N. Zhang, W.W. Guo, Analysis of resonance mechanism and conditions of train-bridge system,Journal of Sound and Vibration 297 (2006) 810-822. 
[9] N. Zhang, H. Xia, W.W. Guo, Vehicle-bridge interaction analysis under high-speed trains, Journal of Sound and Vibration 309 (2008) 407-425.

[10] J.D. Yau, Y.S. Wu, Y.B. Yang, Impact response of bridges with elastic bearings to moving loads, Journal of Sound and Vibration 248 (2001) 9-30.

[11] Y.B. Yang, C.L. Lin, J.D. Yau, D.W. Chang, Mechanism of resonance and cancellation for train-induced vibrations on bridges with elastic bearings, Journal of Sound and Vibration 269 (2004) 345-360.

[12] Y.B. Yang, C.W. Lin, Vehicle-bridge interaction dynamics and potential applications, Journal of Sound and Vibration 284 (2005) $205-226$.

[13] Q.L. Zhang, A. Vrouwenvelder, J. Wardenier, Numerical simulation of train-bridge interactive dynamics, Journal of Computers and Structures 79 (2001) $1059-1075$

[14] Y.S. Lee, S.H. Kim, Structural analysis of 3D high-speed train-bridge interactions for simple train load models, Vehicle System Dynamics 48 (2010) $263-281$.

[15] A. Castellani, G. Kajon, P. Panzeri, P. Pezzoli, Elastomeric materials used for vibration isolation of railway lines, Journal of Engineering Mechanics 124 (1998) 614-621.

[16] F. Cui, C.H. Chew, The effectiveness of floating slab track system—part I: receptance methods, Applied Acoustics 61 (2000) 441-453.

[17] H.E.M. Hunt, Modelling of rail vehicles and track for calculation of ground-vibration transmission into buildings, Journal of Sound and Vibration 193 (1996) 185-194.

[18] M.F.M. Hussein, H.E.M. Hunt, Modelling of floating-slab tracks with continuous slabs under oscillating moving loads, Journal of Sound and Vibration 297 (2006) 37-54.

[19] T. Xin, L. Gao, J.J. Qu, Research on vibration characteristics of floating slab track in rail transportation system, Proceedings of the Third International Symposium on Environmental Vibrations, Taipei, November 2007, pp. 538-543. 